\title{
Transforming Engineering Education by Making the Lecture Pedagogically Attractive, Interesting and Stimulating
}

\author{
S. K. Jha ${ }^{1}$ \\ ${ }^{1}$ Division of Instrumentation and Control Engineering, \\ NSIT, Dwarka, New Delhi. \\ ${ }^{1}$ jhask271@gmail.com
}

\begin{abstract}
Main objective of this paper is to ponder over the most invigorating and indispensable part of engineering education. Unlike arts subject, science is based on systematic and logic based knowledge. Many students develop inhibition and fear psychosis due to lack of pedagogically stimulating dispensation of class lecture. Study of science may work as a great stress buster if pedagogically simple and attractive method is devised. In this paper many examples such as that of mathematics and control problems are taken and how these can be made pedagogically attractive have been highlighted. To start with example of simple mathematics such as LCM (Least Common Multiple) and HCF (Highest Common Factor) has been taken and a warm touch has been given as to how an invigorating pedagogy may kindle the passion of even formative children. Subsequently some examples of probability theory and control system problems are taken just to buttress the fact that science devoid with empathetic and humane pedagogy may make even the simpler subject more complex one.
\end{abstract}

Keywords: Control problems, Mathematics, Bayes Theorem, Pedagogy, Nyquist Stability Criterion, Science

\footnotetext{
S. K. Jha ${ }^{1}$

${ }^{1}$ Division of Instrumentation and Control Engineering,

NSIT, Dwarka, New Delhi.

1 jhask271@gmail.com
}

\section{Introduction}

Evolution of modern science and technology took place from basic form of science. From time immemorial our ancestors faced many predicaments and hardships and endeavoured diligently in an unswerving way which eventually culminated in the form of modern science and technology [1-24]. If our forefathers charismatically appear all of a sudden, then all these modern marvels of science will be spectacles and wonders for them. As the maxim goes: 'Rome was not build in a day' and so does the evolution of science. We have reached to this amazing level of science only exploiting a negligible fraction of this huge population. If negligible fraction of population could bring about this form of scientific spectacle then what will happen if substantive fraction of human population may synergistically be energized to pay undivided attention towards science and technology. Ironically, the way scientific achievement ought to have brought about transformations in human life is not perceptible. Scientific miracles notwithstanding, peoples are under distress and melancholy. It was this undercurrent of thought process that culminated as [1]. It has been observed that in order to understand the complex aspect of science and technology as in [2-16], we require paradigm change in the pedagogy.

Observing the indispensability of science and technology in our day to day life every parent wants their offspring to jump on the bandwagon of science streams. As I belong to underprivileged rural background, I am aware of the whopping drop-out rates of students especially in science streams. Wearer knows where the shoe pinches. As far as my inclination towards science is concerned, it in itself is very interesting. I crammed many scientific laws at first sight and then heuristically ruminated the pragmatic aspect of this law and when well understood my joy knew no bounds. This inveterate and steadfast investigation towards learning methodology especially in context with downtrodden and underprivileged children, I learnt very scintillating findings. I learnt that if we really want the education of science and technology accessible to larger portions of masses then we need to kindle the interest towards science. 
In order to kindle and whittle the interest of students towards science we have to make him/her understand even the complex aspect of science in a simpler and stimulating way. One great physicist Henry Poincare once said- "We study nature because nature is interesting, if it were not interesting why would have we studied it". But ironically many students are not finding study of science interesting because of lack of humane teacher and stimulating pedagogy. It is my conviction that even the complex topic may be comprehended by taking recourse to simple examples.

It is said that Einstein like scientist takes born after each 1000 years. So likewise each person is not predestined with this sort of ingenious and dexterous brain but even so their dormant talent may be stirred up by bringing about magical change in the pedagogy so that teachers may be accordingly trained towards making science funny, interesting and inquisitive. Here, by taking several examples it has been tried to portray that how the fear towards study of even the harder subject may be allayed completely by pedagogical improvement. First of all attention has been focused upon the stage when children pass through most of his cognitive and formative phases of their lives. To start with example of simple mathematics such as LCM (Least Common Multiple) and HCF (Highest Common Factor) has been taken and a warm touch has been given as to how an invigorating pedagogy may kindle the passion of even formative children. Subsequently some examples of probability theory and control system problems are taken just to buttress the fact that science devoid with empathetic and humane pedagogy may make even the simpler subject more complex one.

\section{Case Studies of Pedagogical Aspects Involved in $\mathrm{LCM}$ and HCF}

When I interacted with the numerous students, I found that many of them were unaware about the practicality of LCM \& HCF and they rued about the fact that mathematics is quite uninteresting subject. When asked they expeditiously solved the problem but couldn't practically relate it with day to day examples. When I gave some basic examples as enumerated below they found it invigorating one and then came to know about the true implication of LCM \& HCF to name a few in our practical life problem. This way their interest and curiosity got sparkled and they find it motivating and stimulating one.

Example-1 Four bells toll after an interval of 8, 9, 12, and 15 seconds respectively. If at start they tolled simultaneously at 10 a.m. in the morning, when will they toll simultaneously again?

When this example was asked many couldn't still understand the implication contained in the problem and when they were provided inkling that this has something to do with LCM of all the numbers then they expeditiously found the answer but still had some doubt. Then I simplified the problem further as below and asked for answer again.
Two bells toll after an interval of 2 and 3 seconds respectively. If at start they tolled simultaneously at 10 a.m. in the morning, when will they toll simultaneously again?

I asked them to draw two lines indicating times and mark the line at the interval of $2 \mathrm{sec}$ and $3 \mathrm{sec}$ respectively. When they did it, without calculating the LCM they joyfully gave answer as $6 \mathrm{sec}$. Then I asked them that 6 is nothing but LCM of 2 and 3. In the same way if they extrapolate this concept over original problem they could understand the practical implication of LCM in day to day life and then confidence was vividly discernible on their faces.

Example-2 A rectangle courtyard is $20 \mathrm{~m}$ long and $15 \mathrm{~m}$ broad. It is to be paved with square tiles of same size. Find the number of square tiles required.

Again they were not sure as to how to find the answer but when analogy was given of Example-1 and practical implication of HCF was explained they quickly found the answer as 12 by calculating the HCF of length and breadth as 5 and by dividing the area of rectangle courtyard by the area of square tiles.

\section{Case Studies of Pedagogical Aspects Involved In Conditional Probabilities And Inverse Probabilities (Bayes' Theorem)}

There are two approaches that are followed by teachers. First is that they write the statement and expression of Bayes' theorem and solve the problem directly without providing comprehensive implication or practicality of the theorem. Other approach is not only to write the statement and expression of theorem but analogically explain its difference with the conditional probabilities and prove the veracity of the theorem by Venn diagram and then solve the problem. If they are made to acquaint with heart touching examples with clarity of symbiosis with theorem and its crystal clear proof, they find it more invigorating and get attached with the problem.

In my class room teaching, I tried to pedagogically measure the relative efficacy of two methods. In the $1^{\text {st }}$ approach students were seemingly distressed and their faces were strenuous but in the $2^{\text {nd }}$ approach they were seemingly joyful and confident. Obviously $2^{\text {nd }}$ approach was pedagogically more invigorating and stimulating one. These can be illustrated as below:

\section{A. $\mathbf{1}^{\text {st }}$ Approach:}

BAYE'S THEOREM: If $H_{1}, H_{2}, \ldots, H_{n}$ form a set of mutually exclusive and exhaustive events, with non-zero probabilities, of a random experiment, and $E$ is any other event of the same experiment with $P(E)>0$, then

$P\left(H_{i} / E\right)=\frac{P\left(E / H_{i}\right) \cdot P\left(H_{i}\right)}{\sum_{i=1}^{n} P\left(E / H_{i}\right) \cdot P\left(H_{i}\right)}$

Example-1 In an office there are $25 \%$ graduate and $75 \%$ non-graduates. If $16 \%$ of the graduates and $12 \%$ of the non-graduates are singers, what is the probability that he is a graduate? 


$$
\begin{array}{lll}
\text { Soln. } & P(G)=\frac{25}{100}=1 / 4, & P(\bar{G})=\frac{75}{100}=3 / 4 \\
& P(S / G)=\frac{16}{100}=4 / 25, & P(S / \bar{G})=\frac{12}{100}=3 / 25
\end{array}
$$

Therefore the probability of the man being selected is a graduate given that he is a singer is

$$
\frac{\frac{1}{4} \times \frac{4}{25}}{\left(\frac{1}{4} \times \frac{4}{25}\right)+\left(\frac{3}{4} \times \frac{3}{25}\right)}=\frac{4}{13}
$$

\section{B. $2^{\text {nd }}$ Approach:}

If one person is selected at random, two questions are possible,

(i) The person selected is a graduate. What is the probability that he is a singer?

(ii) The person selected is a singer, what is the probability that he is graduate?

The former comes under conditional probability and may be solved by conditional probability concept and answer will be given simply as

$$
P(S / G)=\frac{16}{100}=4 / 25
$$

The latter is known as inverse probability and in order to calculate the required probability, Bayes' Theorem will be used. In order to understand the problem clearly, proof of Bayes' theorem will be understood clearly which will give better insight about the problem and its symbiosis with Bayes' theorem.

\section{Proof of Bayes' Theorem:}

Let $S$ be the sample space of the random experiment. Since $H_{1}, H_{2}, \ldots, H_{n}$ form mutually exclusive and exhaustive events, we have

$H_{i} \cap H_{j}=\phi \quad$ for $i \neq j$, and $S=H_{1} \cup H_{2} \cup \ldots \cup H_{n}$.

Therefore

$$
\begin{gathered}
E=E \cap S=E \cap\left(H_{1} \cup H_{2} \cup \ldots \cup H_{n}\right) \\
=\left(E \cap H_{1}\right) \cup\left(E \cap H_{2}\right) \cup \ldots \cup\left(E \cap H_{n}\right) .
\end{gathered}
$$

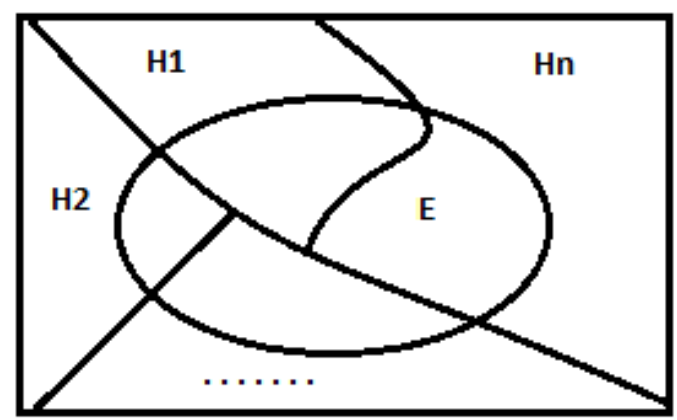

Therefore

$$
\begin{aligned}
& P(E)=P\left[\left(E \cap H_{1}\right) \cup\left(E \cap H_{2}\right) \cup \ldots \cup\left(E \cap H_{n}\right)\right] \\
& \quad=P\left(E \cap H_{1}\right)+P\left(E \cap H_{2}\right)+\cdots+P\left(E \cap H_{n}\right)
\end{aligned}
$$

[Since $\left(E \cap H_{1}\right),\left(E \cap H_{2}\right), \ldots\left(E \cap H_{n}\right)$ are mutually exclusive]

$$
\begin{gathered}
=P\left(E / H_{1}\right) \cdot P\left(H_{1}\right)+P\left(E / H_{2}\right) P\left(H_{2}\right)+\cdots \\
+P\left(E / H_{n}\right) \cdot P\left(H_{n}\right)
\end{gathered}
$$

[By multiplication Theorem]

$$
=\sum_{i=1}^{n} P\left(E / H_{i}\right) \cdot P\left(H_{i}\right)
$$

Therefore

$$
\begin{array}{r}
P\left(H_{i} / E\right)=\frac{P\left(E \cap H_{i}\right)}{P(E)}=\frac{P\left(E / H_{i}\right) \cdot P\left(H_{i}\right)}{P(E)} \\
=\frac{P\left(E / H_{i}\right) \cdot P\left(H_{i}\right)}{\sum_{i=1}^{n} P\left(E / H_{i}\right) \cdot P\left(H_{i}\right)}
\end{array}
$$

Hence the Bayes' theorem is proved. Now pedagogically suitable step for solution of same example are illustrated below.

\section{Pedagogically suitable step for solution:}

Let $\quad H_{1}=$ The event of choosing graduates;

$\mathrm{H}_{2}=$ The event of choosing non-graduates;

And $E=$ The event of choosing singer

Then, $P\left(H_{1}\right)=\frac{25}{100}=1 / 4, P\left(H_{2}\right)=\frac{75}{100}=3 / 4$

Also $P\left(E / H_{1}\right)=$ Event of selecting a singer given that he is graduate $=\frac{16}{100}=4 / 25$

$P\left(E / H_{2}\right)=$ Event of selecting a singer given that he is non-graduate $=\frac{12}{100}=3 / 25$

Therefore the probability of the man being selected be graduate given that he is a singer

$$
\begin{gathered}
P\left(H_{1} / E\right)=\frac{P\left(E / H_{1}\right) \cdot P\left(H_{1}\right)}{P\left(E / H_{1}\right) \cdot P\left(H_{1}\right)+P\left(E / H_{2}\right) \cdot P\left(H_{2}\right)} \\
=\frac{\frac{4}{25} \times \frac{1}{4}}{\left(\frac{4}{25} \times \frac{1}{4}\right)+\left(\frac{3}{25} \times \frac{3}{4}\right)}=\frac{4}{13}
\end{gathered}
$$

Thus now the students have crystal clear concept towards the application of Bayes' theorem and its application in solving the problems. Ingenious and dexterous brain clicks the crux very expeditiously but normal and average brain is not found to be so agile which I have experienced in my hitherto life and for them to be able to grasp, understand and appreciate the problem, only well researched pedagogically suitable and viable method need to be devised and teacher need to be accordingly trained if we really want the benefit of education to be accessible by the common masses of the third world countries.

\section{Case Studies of Pedagogical Aspects Involved in Control Systems}

As far as study of feedback control system is concerned many author incessantly and monotonously describes the theoretical aspects of control systems without providing any insight about practical aspects of control systems. They go on dealing with the circumlocutive mathematics to describe many control aspects and keep the student guessing as to where all these tools of control system will be used. When I retrospectively visualize our college days 
it is quite haunting and disgustful. We were really not enjoying solving the control problem. We were studying it as if we are students of mathematics. Now it gives me vicarious pleasure when I teach the same subject by bringing about and introducing pedagogical improvement by incorporating a practical example where all the principles of control systems are involved. Thus I introduced "Continuous Stirred Tank Reactor" example in the very first class explaining it thoroughly by drawing its corresponding block diagram that gives better insight to students. This being the best example of feedback control system got the students fascinated towards the subject.

Similarly while dealing with Root Locus topic of control problem, there are two methods by which this subject may be taught. First method is cramming every rules of root locus construction and then draws the same expeditiously. Second method may be to understand the evolutionary details of all the rules and then solve the problems. Though problem may be solved by both the method but the second method is more invigorating.

In the same way while dealing with Nyquist stability criterion, many students are not able to comprehend as to why we take Nyquist path as entire right half s-plane in the form of infinite semicircular arc. Many teachers are not able to provide very cogent reply to this question. So I have devised some pedagogically invigorating and interesting method to make the students understand it in a better way. I generally provide them the example of police who devise their own methodology to deal with the law and order problem. What does a police do to deal with the law and order problem? They always keep track records of dreaded criminals who are more likely to create law and order problem. So by keeping regulatory mechanism over those problematic gangsters, they are able to maintain peace and tranquility in the designated area. So taking analogy from this example, Nyquist took only problematic poles and zeros into consideration. As we know that it is only right half closed loop poles which create stability problem hence analogically entire right half s-plane was taken into consideration. Apparent joy was discernible on the face of the students. So this way I found that many otherwise difficult control problems may be simplified by analogically evoking simple and invigorating example.

Similarly while understanding the time response analysis of $1^{\text {st }}$ and $2^{\text {nd }}$ order system, there may be infinite number of system which may be of $1^{\text {st }}$ and second order type but most simple and easiest in understanding is R-L-C series or parallel circuit. So by making different combination of these elements, $1^{\text {st }}$ and $2^{\text {nd }}$ order systems may be easily formed and corresponding transfer function may easily be found out. After finding the transfer function it is easy to understand the implication of damping ratio and undamped natural frequency in terms of these basic energy storing and dissipating elements. As there is great analogy between electrical and other form of system such as mechanical, thermal and pneumatic systems etc., the concept may be easily extrapolated from electrical to other systems. In fact, analysis of electrical system is comparatively easier, that is why it is pedagogically advisable to start with electrical system and then analogically it be extended to other system.
The students were observed to be relishing this pedagogically improved method.

\section{How and Why the Invigorating Pedagogy?}

In fact any learner with the passage of time, gains sufficient knowledge about any subject but after long gap he forgets about the difficulty being faced by him in the initial phases. If a sensible person, having normal brain level, goes in retrospection of past life then he must be able to recall the difficulties of understanding the true implication of something in initial stages. In my view, a conscientious person should ponder over this vital fact and make meticulous effort in simplifying the reading material so that any new beginner may understand it without too much effort. I have meticulously experienced that the main reason of dropouts in village or urban areas is that those who are devoid of money and hence a good teacher, leaves the study in the beginning itself because everything looks Greek to them. So educationist has to play pivotal role in designing the curriculum and learning material in such a way that even without the availability of good teacher, students get magnetically attracted towards the books.

\section{Conclusions}

Researchers have found that the main reason of dropouts from schools or colleges by students is lack of invigorating pedagogy. Hence the main objective of this paper is to ponder over the most invigorating and indispensable part of engineering education. Unlike arts subject, science is based on systematic and logic based knowledge. Many students develop inhibition and fear psychosis due to lack of pedagogically stimulating dispensation of class lecture. Study of science may work as a great stress buster if pedagogically simple and attractive method is devised. In this paper many examples such as that of mathematics and control problems are taken and how these can be made pedagogically attractive have been highlighted.To start with example of simple mathematics such as LCM (Least Common Multiple) and HCF (Highest Common Factor) has been taken and a warm touch has been given as to how an invigorating pedagogy may kindle the passion of even formative children. Subsequently some examples of probability theory and control system problems are taken just to buttress the fact that science devoid with empathetic and humane pedagogy may make even the simpler subject more complex one. Ingenious and dexterous brain clicks the crux very expeditiously but normal and average brain is not found to be so agile, which I have experienced in my hitherto life and for them to be able to grasp, understand and appreciate the problem, only well researched pedagogically suitable and viable method need to be devised and teacher need to be accordingly trained if we really want the benefit of education to be accessible by the common masses of the third world countries.

\section{Acknowledgement}

The author wish to pay obeisance to the ancient order of monks of India and its rich cultural heritage which gave inspiration to ruminate over such topics which is indispensable and invaluable for mankind. Due thanks are also to numerous dedicated scientist and saints of other 
parts of the world who worked tirelessly in the field of upliftment of marginalized section of society but for whom this kind of great topic such as pedagogical improvement won't have been envisaged and conceptualized. After all this is the sole purpose of any social reformer as to what appropriate measures be taken so that the true benefit of education reaches unto last persons sitting at the fences. Moreover, if education is penetrated homogeneously and uniformly in a dispassionate way to every corners of the world then all these anti-social activities will automatically vanish from the world. Alas!This were the motive of the world leaders, world would have been something different from what we see today.

\section{References}

[1] Jha,S. K. Yadav,A.K. Gaur,Prerna and Gupta, J.R.P. (2014) "Robust Stability Analysis of DC Servo Motor for Attitude Control of Aircraft using Arguon's Theorem," Journal of Control Engineering and Technology, vol. 4, issue 2, pp. 127-134.

[2] Tan,N. and Atherton,D. P. (2000) "Stability, and performance analysis in an uncertain world," IET Comput. Control Eng. J., vol.11, no.2, pp.91-101.

[3] Bhattacharyya,S. P., Datta,Aniruddha, and Keel,L. H. (2009) "Linear Control Theory: Structure, Robustness and Optimization", CRC Press, Taylor and Francis Group, New York.

[4] Doyle,J. C. and Stein, G.(1981) "Multivariable Feedback Design: Concepts for a Classical/Modern Synthesis," IEEE Transaction on Automatic Control, AC- 26 (1), pp. 4-16.

[5] Jha, S. K. Yadav, A. K. Gaur, Prerna. Parthsarathy, H. and Gupta, J.R.P. (2014), "Robust and Optimal Control Analysis of Sun Seeker System," Journal of Control Engineering and Applied Informatics, Vol.16, No.1, pp. 70-79.

[6] Yadav,A.K. Gaur, Prerna. Jha,S. K. Gupta, J.R.P. and Mittal, A. P. (2011), "Optimal Speed Control of Hybrid Electric vehicle," Journal of Power Electronics, vol. 11, no. 4, pp. 393-400.

[7] Kirk, D.E. (1970)Optimal Control Theory: AN INTRODUCTION,Prentice Hall, Englewood cliffs, New Jersey.

[8] Keel,L. H. and Bhattacharyya,S. P. (1997) "Robust, Fragile or Optimal?," IEEE Trans. Automat. Contr., vol. AC-42, no. 8, pp. 1098-1105.

[9] Jha,S. K. Parthsarathy,H. Gupta,J. R. P. and Gaur,P. (2011), "Verification of the Veracity of Brachistochrone Curve and Evolution of Optimal Control," India International Conference on Power Electronics (IICPE), N. Delhi, India, pp. 1-4.

[10] Ogata, K. (1997),Modern Control Engineering, Prentice Hall, USA, Third Edition, 1997.

[11] Richardson,K. I. T. (1954) "The Gyroscope Applied," The Philosophical Library, New York, pp. 261-264.

[12] McRuer,D. and Graham,D. (1981) "Eighty Years of Flight Control: Triumphs and Pitfalls of the System Approach," Journal of Guidance and Control, vol. 4.

[13] Kuo,B. C. and Golnaraghi,Farid (2003) Automatic Control System, John Wiley and Sons (Asia) Pte Ltd, Eighth Edition.

[14] Zadeh, L. A. (1984) "Making computer think like people," IEEE Spectrum, 21, pp. 26-32.

[15] Pushpkant and Jha,S. K. (2013) "Performance Analysis of Conventional, Modern and Intelligent Control
Techniques for Controlling CNC Machine Tool," International Journal of Applied Engineering Research, vol. 8, no. 6, pp. 51-55.

[16] Tan,N. and Atherton,D. P. (2000) "Stability and performance analysis in an uncertain world," Computing and Control Engineering Journal, pp. 91101.

[17] Jha, S. K. Yadav, A. K. Gaur, Prerna. Parthsarathy, H. and Gupta, J.R.P. (2014), "Robust and Optimal Control Analysis of Sun Seeker System," Journal of Control Engineering and Applied Informatics, Vol.16, No.1, pp. 70-79.

[18] Yadav, A. K. and Gaur,P. (2013) "Comparative analysis of modern control and AI-based control for maintaining constant ambient temperature," World Review of Science, Technology and Sustainable Development, vol. 10, Nos. 1/2/3, pp. 56-77.

[19] Husain,Iqbal (2011) Electric and Hybrid Vehicles, Design Fundamentals (2nd edition), CRC Press, Taylor and Francis Group, New York.

[20] U.S. Environmental Protection Agency (EPA), (1994) "Automobile emissions: An overview," EPA 400-F92-007, Fact Sheet OMS-5.

[21] Doniger,D. Friedman,D. Hwang, R. Losof,D. and Mark,J. (2002) "Dangerous Addiction: Ending America's Oil Dependence," National Resources Defense Council and Union of Concerned Scientists.

[22] Ehsani, M. Gao, Y. and Emadi,Ali (2011) Modern Electric, Hybrid Electric, and fuel Cell VehiclesFundamentals, Theory, and Design, $2^{\text {nd }}$ Edition, CRC Press, Florida.

[23] Larminie,J. and Lowry,J. (2012)Electric Vehicle Technology Explained, John Wiley \& Sons, U.K.

[24] Jha,S. K. and Jha,R. (2012) "Investigating The Indispensability of Renewable Energy Sources from the Standpoint of Conservation of Ecology and Environment," Invertis Journal of Renewable Energy, vol. 2, no. 4, pp. 219-233.

[25] Times of India, Speaking Tree, Sunday times sources.

[26] Srimadbhagwadgita sources.

[27] An Autobiography of Gandhi: The Story of My Experiment With Truth.

[28] Jha, S. K. (2015)“Transforming Engineering Education Exploiting Inveterate Symbiosis Between Science and Spirituality," Journal of Engineering Education Transformation (JEET), Vol. 29, issue 2, pp. 25-30. 